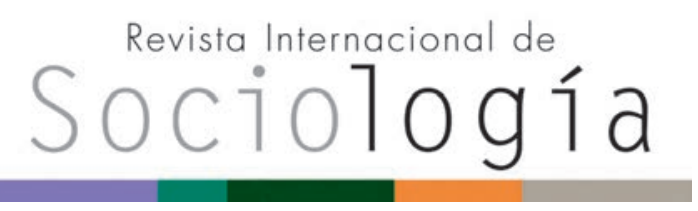

Revista Internacional de Sociología RIS vol. 75 (2), e062, abril-junio, 2017, ISSN-L:0034-9712 doi: http://dx.doi.org/10.3989/ris.2017.75.2.15.140

\title{
ELECCIONES MUNICIPALES EN ESPAÑA
}

\section{La personalización del voto}

\author{
LOCAL ELECTIONS IN SPAIN \\ The Personalization of Voting Behavior
}

\author{
Pedro Riera Sagrera \\ Universidad Carlos III de Madrid, España. \\ PRiera@clio.uc3m.es | ORCID iD: http://orcid.org/0000-0001-5315-0350
}

Raúl Gómez Martínez

Universidad de Liverpool, Reino Unido.

raul.gomez@liverpool.ac.uk | ORCID iD: http://orcid.org/0000-0002-6810-0628

Juan Antonio Mayoral Díaz-Asensio

Universidad de Copenhague, Dinamarca

juan.mayoral@jur.ku.dk | ORCID iD: http://orcid.org/0000-0002-7192-3967

Pablo Barberá Aragüena

Universidad del Sur de California , Los Ángeles, Estados Unidos

pablo.barbera@nyu.edu | ORCID iD: http://orcid.org/0000-0002-9063-4829

José Ramón Montero Gibert

Universidad Autónoma de Madrid, España

joseramon.montero@uam.es | ORCID iD: http://orcid.org/0000-0002-8507-0192

Cómo citar este artículo / Riera Sagrera, P., R. Gómez Martínez, J. A. Mayoral Díaz-Asensio, P. Barberá Aragüena y J. R. Montero Gilbert. 2017. "Elecciones municipales en España. La personalización del voto". Revista Internacional de Sociología 75 (2): e062. doi: http://dx.doi.org/10.3989/ ris.2017.75.2.15.140

\section{Resumen \\ Cuando los ciudadanos votan en elecciones municipales, ¿tienen en cuenta solo factores a nivel nacional? $\mathrm{O}$, por el contrario, ¿prestan también atención a elementos de carácter local? En este artículo sostenemos que la eva- luación que hacen los ciudadanos de los candidatos a la alcaldía es un factor particularmente importante para explicar el sentido del voto en las elecciones locales en España. Para verificar empíricamente la existencia de esta relación, analizamos las elecciones de 1999, 2007 y 2011. Examinando una muestra relativamente hetero- génea de municipios y gracias a las encuestas del Centro de Investigaciones Sociológicas, demostramos el efecto de las evaluaciones de los candidatos a expensas de un papel menos pronunciado de la ideología. La evidencia aportada también apunta a que este patrón es más fuerte en municipios pequeños y para elecciones más recientes.}

\section{Palabras Clave}

Candidatos; Elecciones de segundo orden; Elecciones locales; España; Personalización.
Copyright: (C) 2017 CSIC. Este es un artículo de acceso abierto distribuido bajo los términos de la licencia Creative Commons Attribution (CC BY) España 3.0.

Recibido: 11/09/2015. Aceptado: 01/07/2016. Publicado online: 24/05/2017

\section{Abstract}

When voters cast their ballot in local elections, are they only taking into account national factors? Or do they, to the contrary, also pay attention to local elements? In this article we argue that voters' evaluations of candidates for mayor are particularly important to explain party choice in this type of subnational elections in Spain. To empirically verify the existence of this relationship, we focus on the 1999, 2007, and 2011 elections. By dwell-ing on a relatively heterogeneous sample of municipali-ties and working with surveys undertaken by the Centro de Investigaciones Sociológicas, we show the effect of candidates' evaluations at the expense of a less pronounced role of ideology. The provided evidence also suggests that this pattern becomes stronger in small municipalities and more recent elections.

\section{KeYWORDS}

Candidates; Local elections; Personalization; Secondorder elections; Spain. 


\section{INTRODUCCIÓN}

En este trabajo ${ }^{1}$ examinaremos el impacto electoral a nivel local de las características de los líderes políticos ${ }^{2}$. Para ello analizaremos la medida en la que la propensión a votar a un determinado partido en las elecciones municipales está relacionada con la valoración que hacen los votantes de su candidato a la alcaldía. El papel de los líderes en la decisión del voto es una cuestión clásica en los estudios electorales. Numerosos autores han destacado la relevancia de los candidatos a la hora de determinar quién gana y quién pierde las elecciones (King 2002; Rico 2009) Sin embargo, estos efectos comunes deben ser diferenciados según las características de cada tipo de elección (Burden y Wichowsky 2010). En este artículo analizaremos aquellos factores que dotan a la valoración de los candidatos de mayor relevancia e impacto sobre el voto a nivel local en comparación con las elecciones a nivel nacional o autonómico. Discutiremos también cómo este efecto varía en función de la proximidad de los candidatos locales a los ciudadanos, una proximidad medida a través del tamaño del municipio: cuanto menor sea el número de habitantes en el municipio, mayor será, en principio, la influencia en el voto de las características del candidato. Analizaremos esta influencia junto a otras características de tipo sociodemográfico y político tales como la educación, la situación laboral y el sexo de los votantes. Nuestras expectativas también plantean que la ideología será menos importante cuanto menor sea el tamaño del municipio. $Y$ abordaremos además la cuestión de si existe una creciente personalización del voto en las elecciones municipales españolas. ¿Son las valoraciones de los candidatos a alcalde cada vez más importantes a la hora de decidir a quién se vota en este tipo de comicios? ¿O permanece la arena local en España ajena a este proceso registrado en otros contextos?

Las elecciones municipales han sido un objeto de estudio poco investigado en el marco de la ciencia política (Marschall, Sha y Runil 2011). Y si en muchos sistemas democráticos el campo de las elecciones municipales permanece, como se ha dicho, en su infancia (Krebs 2014: 189), en España la situación no es mucho mejor. Los únicos estudios empíricos sobre el comportamiento electoral a nivel local se centran, que sepamos, en una sola elección y en cuatro ciudades (Barberá 2010), o en una comunidad autónoma (Martínez Fuentes y Ortega 2010a), o utilizan únicamente datos a nivel agregado (Delgado 1997; 2010). Nosotros iremos un poco más allá y utilizaremos datos individuales relativos a tres elecciones y 15 localidades. De esta manera, podremos comprobar mejor, no solo si el poder explicativo de nuestras principales variables independientes (valoración de los candidatos e ideología) depende del tamaño del municipio, sino también si existe una creciente personalización del voto.
El resto del artículo está dividido en cinco secciones. En las dos siguientes se presentan los argumentos teóricos de la investigación y las hipótesis de trabajo. A continuación, se justifica la selección de casos y se describen los datos utilizados. La cuarta sección discute los resultados del análisis empírico. Por último, las conclusiones recogen los hallazgos principales del trabajo enmarcándolos en el estudio del comportamiento electoral a nivel local en nuestro país.

\section{Candidatos y contexto municipal}

En términos generales, la literatura sobre el efecto de los candidatos sobre el voto trata de proporcionar una respuesta de carácter normativo a la cuestión de cómo los procesos electorales determinan, no solo qué políticas deben llevarse a cabo, sino también quién debe llevarlas a cabo. Esta respuesta está a su vez condicionada por la perspectiva desde la que se contemple la relevancia de los líderes políticos en procesos electorales. Existen dos perspectivas principales. Una de ellas, la de las elecciones de segundo orden (Reif y Schmitt 1980), aplicable típicamente a las europeas pero también a las locales, carece de interés para nuestros objetivos. La otra, la de la personalización de la política, en parte coincidente con el fenómeno de la presidencialización de las elecciones en países como Estados Unidos, resulta obligado abordarla.

De acuerdo con esta segunda perspectiva, la denominada personalización o presidencialización de la política consiste en la relevancia adquirida por los candidatos y líderes en la dirección de sus partidos, en la acción de gobierno y en la competición electoral (Mughan 1993; Hazan 1996; Maddens y Fiers 2004; Poguntke y Webb 2005; Costa Lobo 2014). Guillem Rico (2009: 13 y 23) ha caracterizado a la personalización como "el creciente impacto de los líderes en las decisiones de los votantes en relación al peso de otros factores, y en particular el de las identidades partidistas y otras predisposiciones políticas"; afecta a "la manera en que los ciudadanos procesan la información política, la forma en que ven a los partidos, juzgan a los gobiernos y se forman opiniones sobre los temas de debate político". En un principio, la forma de gobierno fue considerada importante para explicar este fenómeno (Bartle y Crewe 2002; Brettschneider y Gabriel 2002). Sin embargo, la tendencia a la personalización tanto institucional como electoral de los sistemas presidenciales ha dejado de ser monopolio exclusivo de estos últimos sistemas en los tiempos actuales para extenderse a los parlamentarios (McAllister 2009; Costa Lobo y Curtice 2014), y un número cada vez mayor de trabajos ha estudiado el impacto de candidatos y líderes también en elecciones legislativas (Graetz y McAIlister 1987; Bean 1993; Clarke 2000). Ese impacto varía considerablemente según partidos y elecciones. Resulta sustancial en el caso de los grandes 
partidos y de los países con un peso decreciente de los cleavages sociales (Gunther y Montero 2001). Y puede también comprobarse en las valoraciones que los votantes hacen de los candidatos según ciertos rasgos específicos, lo que les permite formarse una opinión global sobre su calidad y posible desempeño una vez lleguen al Gobierno. Se trata, además, de un patrón con un fuerte componente dinámico, ya que los electores tienden crecientemente a votar por una persona en lugar de por un programa o por unas siglas (Manin 1997; Aarts, Blais y Schmitt 2011).

El caso español no ha sido una excepción en estos procesos de personalización/presidencialización de la política. Desde el inicio del nuevo periodo democrático, los líderes políticos y los dirigentes partidistas gozan de niveles extraordinarios de poder e influencia, controlan con mano de hierro la organización de sus formaciones y disfrutan de una autonomía virtualmente completa a la hora de diseñar candidaturas y campañas electorales (Gunther, Sani y Shabad 1986: cap. 8; van Biezen y Hopkin 2005). Ha podido así subrayarse, en consonancia con lo anterior, la notable influencia en el voto de líderes carismáticos como Felipe González, José María Aznar o José Luis Rodríguez Zapatero, capaces de atraer el apoyo de ciudadanos indecisos y de hacerlo además en momentos críticos para su partido (Barreiro y Sánchez-Cuenca 1998; Rico 2007; 2011; Orriols y Lavezzolo 2008).

Una buena parte de esta literatura está centrada en contextos de tipo nacional o cuando mucho autonómico. Sin embargo, si en algún nivel se da una estrecha conexión entre la personalización/presidencialización de la política y el voto es en el local. Este vínculo se produce, en primer lugar, por el intenso personalismo del diseño institucional del régimen electoral: por ejemplo, solo los cabezas de las listas electorales pueden competir por la alcaldía. En segundo lugar, la configuración de las elecciones locales, concebidas en clave neopresidencialista por los muy amplios poderes que se atribuyen al alcalde, contribuye a reforzar esta relación (Vanaclocha 1997: 294). Y, finalmente, la personalización se hace sentir con especial fuerza en el ámbito municipal por la relevancia de la figura del alcalde en este nivel: como ha resumido Jordi Capo (1991: 158), los alcaldes "son fuertes, son estables, tienen recursos y capital político".

Además de poder institucional y representativo, los alcaldes, en cuanto candidatos, suelen también liderar la organización local de su partido y concentrar en torno a él la estrategia electoral (Criado y Martínez Fuentes 2009; 2010). En el ámbito municipal, a pesar de la configuración parlamentaria de los comicios y de la adopción de listas cerradas en la mayoría de municipios, la competición electoral se ha desarrollado hasta el momento en clave presidencialista entre candidatos identificados por completo con sus parti- dos (Márquez 2007), mientras que el resto de integrantes de la lista local aspira simplemente a obtener concejalías. Los partidos tratan consecuentemente de seleccionar a personas conocidas en la localidad, especialmente cuando el propio partido carece de implantación dentro del municipio, para capitalizar así su popularidad y atraer votos (Natera 2001; Martínez Fuentes 2008). Dicho de otra forma, la campaña electoral tiene lugar exclusivamente en torno a la figura del candidato al mismo tiempo que también es dirigida por este. El fenómeno se traduce sobre todo en dos factores comunes en la competición política: la tendencia a resaltar las cualidades y trayectoria social, económica y política del candidato a la alcaldía, mientras que el resto de miembros de la lista es relegado a un segundo plano, y la discreción de los candidatos locales para "singularizar" su programa y discurso complementando las consignas provenientes de niveles nacionales o de cargos superiores del partido (Criado y Martínez Fuentes 2010). Esta personalización confiere a los candidatos la posibilidad de crear, tanto en el municipio como en el partido, relaciones de poder que agrandan su figura más allá de su ámbito local; ha llegado así a hablarse de la existencia en el interior de los partidos de una especie de alcaldización por medio de la cual algunos alcaldes se convierten en figuras políticas nacionales (Martínez Fuentes y Ortega 2010b: 12). Además, los candidatos locales gozan a priori de una gran cercanía a los electores, lo que les confiere una accesibilidad que contrasta con la distancia inevitable respecto a quienes compiten en elecciones generales (Barberá 2010). La proximidad de los candidatos a los ciudadanos, y el recurso a situaciones de trato directo en contextos de competición centrada en los primeros, convierten a las características de los líderes municipales y a su valoración por parte del electorado en elementos determinantes para la decisión del voto (Freire 2005).

Las elecciones locales enfatizan así el nexo individual de los candidatos con los electores. Ello incrementa a priori su relevancia entre los factores de voto y disminuye el peso de otras motivaciones. En este artículo queremos comprobar la importancia de los líderes locales en el voto a sus partidos. No existen en España, que sepamos, trabajos que analicen empíricamente el peso de la valoración de los candidatos a alcalde en comparación con los restantes determinantes del voto. Esta ausencia se destacaba hace ya más de diez años (Molins y Pardos 2005: 112). Desde entonces ha tratado de cubrirse mediante argumentos especulativos o a través de criterios restrictivos del campo de estudio como la selección de alguna comunidad autónoma o las valoraciones de los líderes nacionales de los dos principales partidos (Delgado 1999; Martínez Fuentes y Ortega 2010a). Los resultados son lógicamente insatisfactorios. En este trabajo intentaremos cubrir aquel vacío a través de las respuestas proporcionadas a tres preguntas. Primera, ¿en qué medida es determinante la valora- 
ción de los líderes municipales? Si lo fuera, ¿hasta qué punto depende dicho efecto del tamaño del municipio? Y, por último, ¿existe también un proceso de creciente personalización del voto en las elecciones municipales en España?

\section{HIPÓTESIS}

Como ya hemos adelantado, esperamos que la valoración de los candidatos locales tenga una influencia significativa en el voto en las elecciones municipales; una influencia que subsista incluso al controlar por la ideología y por otras características sociodemográficas de los votantes. Esperamos asimismo que la importancia de los candidatos sea menor en municipios más grandes (Barberá 2010). Por lo tanto, el tamaño del municipio media el efecto de la personalización en el comportamiento electoral local: cuanto menor sea la localidad, mayor impacto tendrá en el voto la evaluación que hacen los votantes de los candidatos (Delgado 1997: 246). Y, por el contrario, cuanto mayor sea el municipio, más importante resultará el denominado voto ideológico (Gunther y Montero 2001: 126-129).

Los mecanismos que explican el efecto modificador del tamaño de la localidad sobre el impacto de la evaluación de los candidatos están relacionados con la idea de la proximidad entre los ciudadanos y las instituciones políticas (López Nieto y Delgado 1994; Barberá 2010). En los municipios de tamaño reducido, los votantes crean vínculos de cercanía con sus representantes democráticos a través de múltiples canales; a través, por ejemplo, del contacto y las relaciones personales, las oficinas de la Administración local, las sedes locales de los partidos, etc. Estos canales facilitan la adquisición de información sobre los temas políticos locales y sobre las capacidades de los candidatos, especialmente si alguno de ellos ha ocupado ya la alcaldía y es, por lo tanto, suficientemente conocido. Por su parte, los candidatos tratarán de resaltar sus recursos y habilidades para esta labor a lo largo de su gestión en el Gobierno local y durante la campaña electoral.

En los municipios de mayor tamaño, en cambio, la figura del candidato tiende a diluirse. Las grandes ciudades implican que los candidatos tienen que realizar actos de campaña ante un electorado tan numeroso como disperso, lo cual los distancia del votante (Lewis 2011). Desde el punto de vista del ciudadano, la comunicación de sus preferencias y la información sobre las cualidades de los candidatos requieren mayores esfuerzos en grandes localidades, donde las estructuras administrativas son más complejas y burocráticas (Steenbergen y Lodge 2003). Y esta desinformación lleva a los votantes a utilizar otro tipo de mecanismos para decidir su voto, entre los cuales la ideología ocupa un lugar preeminente (Lau y Redlawsk 2006). En estos casos, los votantes confían en los atajos cogni- tivos y pistas informativas que los aproximen a las posiciones fundamentales de los partidos, mucho más accesibles y estables que las características personales de unos candidatos que son solo superficialmente conocidos. Además, es lógico pensar que, a medida que crece el tamaño de la localidad, también lo hace el carácter político de las decisiones que deben tomar los consistorios municipales, dejando espacio para una mayor ideologización del comportamiento electoral de los ciudadanos y restando importancia a las características individuales de los candidatos.

La creciente personalización del voto registrada en las democracias de Europa occidental también se observa en las elecciones municipales en España. De ahí que crezca en el tiempo el impacto de las evaluaciones de los candidatos y decrezca el efecto de la ideología sobre la orientación del voto (Rico 2009). Existen al menos dos mecanismos que explican esta tendencia. En primer lugar, cabe señalar el deterioro considerable de la confianza en los partidos políticos que, en forma de los denominados sentimientos antipartidistas, empieza a registrarse a mediados de la década pasada en nuestro país (Torcal, Montero y Gunther 2003). En un contexto de progresivo descrédito de las formaciones políticas, la teoría de la personalización aparece como una alternativa atractiva para explicar las preferencias electorales de los votantes. En segundo lugar, la creación en muchas localidades de canales de televisión municipales y, en menor medida, de radios, periódicos o revistas locales incrementa la importancia del proceso de personalización del voto. La más que frecuente presencia en estos medios de los líderes partidistas locales, y desde luego de los alcaldes, refuerza su notoriedad y aumenta su atractivo ante los votantes.

En consecuencia, nuestras hipótesis pueden formularse como sigue:

$H_{1}$ : en las elecciones municipales, la valoración de los candidatos tiene un efecto positivo y significativo sobre la probabilidad de votar a un determinado partido.

$H_{2 a}$ : el efecto de la valoración de los candidatos será mayor cuanto menor sea la población de una localidad.

$H_{2 b}$ : el efecto de la ideología crecerá en función del tamaño de la localidad.

$H_{3 a}:$ el efecto de la valoración de los candidatos crecerá a lo largo del tiempo.

$H_{3 b}$ : el efecto de la ideología decrecerá a lo largo del tiempo.

\section{Casos y métodos}

A la hora de estudiar el voto municipal en las localidades para las que disponemos de valoración de los distintos líderes municipales, optaremos por una estrategia doble. En la primera parte de nuestro aná- 
lisis empírico mostraremos los resultados más detallados para cinco grandes ciudades. Y en la segunda parte ampliaremos a 15 el número de localidades con el propósito de introducir posibles factores explicativos que varíen de un municipio a otro. Trabajaremos con las encuestas del banco de datos del Centro de Investigaciones Sociológicas (CIS). Dado que nuestro interés radica en considerar la valoración del líder local en cada uno de los modelos que estimemos, quedarán excluidas las encuestas en las que no figure dicha pregunta.

Los datos disponibles están contenidos en cuatro encuestas: la preelectoral de 1999, la pre- y poselectoral de 2007 y la preelectoral de 2011 (con la excepción de Barcelona, que será, pese a ello, incluida por contar con un cuestionario específico en la poselectoral de 2011). En cuanto a las ciudades para las que mostraremos resultados más específicos, el criterio de selección se ha basado en la disponibili- dad de datos a lo largo de las diversas elecciones. Así, junto con Madrid y Barcelona, hemos elegido todas las ciudades con encuesta propia para las tres elecciones municipales analizadas; son Santiago de Compostela, Sevilla y Vitoria. En el caso de Madrid, no existe encuesta propia con valoración de líderes municipales en 1999, pero decidimos incluirla por su relevancia en términos de gran ciudad, además de por ser el único caso de una ciudad en una comunidad autónoma de régimen general para la que contábamos con valoración de los líderes municipales en 2007. La lista completa de encuestas está incluida en la Tabla $1^{3}$, y la relación de localidades y años está recogida en la Tabla $2^{4}$.

La metodología que emplearemos será diferente en cada una de las dos partes que siguen. En la primera, donde desagregaremos los resultados de las cinco ciudades mencionadas para las elecciones de 1999, 2007 y 2011, emplearemos un modelo de regre-

Tabla 1.

Relación de encuestas utilizadas procedentes del Banco de Datos del Centro de Investigaciones Sociológicas

\begin{tabular}{ll}
\hline Número de encuesta & Título \\
\hline $2340-2348$ & Preelectoral elecciones municipales, 1999, en varias ciudades \\
\hline $2683-2686$ & Preelectoral elecciones municipales, 2007, en varias ciudades \\
\hline 2704 & Preelectoral elecciones municipales, 2007, en Madrid \\
\hline $2720-2723$ & Poselectoral elecciones municipales, 2007, en varias ciudades \\
\hline $2866-2869$ & Preelectoral elecciones municipales, 2011, en varias ciudades \\
\hline 2883 y 2884 & Preelectoral elecciones autonómicas, 2011, en Ceuta y Melilla \\
\hline 2890 & Poselectoral elecciones municipales, 2011, en Barcelona \\
\hline
\end{tabular}

Tabla 2.

Relación de localidades y elecciones incluidas en los análisis empíricos

\begin{tabular}{|c|c|c|c|}
\hline \multirow{2}{*}{ Ciudades } & \multicolumn{3}{|c|}{ Años de las elecciones locales } \\
\hline & 1999 & 2007 & 2011 \\
\hline A Coruña & $\sqrt{ }$ & & \\
\hline Barcelona & $\sqrt{ }$ & $\sqrt{ }$ & $\sqrt{ }$ \\
\hline Bilbao & $\sqrt{ }$ & & \\
\hline Burgos & $\sqrt{ }$ & & \\
\hline Ceuta & & & $\sqrt{ }$ \\
\hline Madrid & & $\sqrt{ }$ & $\sqrt{ }$ \\
\hline Málaga & $\sqrt{ }$ & & \\
\hline Melilla & & & $\sqrt{ }$ \\
\hline San Sebastián & $\sqrt{ }$ & & \\
\hline Santiago de Compostela & $\sqrt{ }$ & $\sqrt{ }$ & $\sqrt{ }$ \\
\hline Sevilla & $\sqrt{ }$ & $\sqrt{ }$ & $\sqrt{ }$ \\
\hline Valencia & & & $\sqrt{ }$ \\
\hline Vigo & $\sqrt{ }$ & & \\
\hline Vitoria & $\sqrt{ }$ & $\sqrt{ }$ & $\sqrt{ }$ \\
\hline Zaragoza & & & $\sqrt{ }$ \\
\hline
\end{tabular}


sión logística condicional con variables específicas por alternativa (McFadden 1974) en el que la variable dependiente es la de haber votado a un partido determinado (1) o no (0). Este tipo de modelos permite la introducción de variables de una doble naturaleza: de un lado, variables que varían para cada una de las alternativas, como es, en nuestro caso, la valoración que el entrevistado hace del líder municipal de cada uno de los partidos; de otro, variables que son específicas de los individuos, como su posición ideológica (medida según la auto-ubicación del entrevistado en la escala izquierda-derecha). Esto nos permite conocer hasta qué punto ambas variables explican el comportamiento electoral de los votantes. En estos modelos incluiremos también otras variables de control que pueden afectar a las decisiones de voto, y que, por lo tanto, podrían introducir sesgos de variables omitidas: sexo (hombre [1] o mujer [0]), edad (en años), nivel educativo (máximo nivel educativo alcanzado; sin estudios [0], primaria no completada [1], primaria [2], secundaria [3], formación profesional [4], estudios medios universitarios [5], estudios superiores [6] y doctorado o equivalente [7]), y situación laboral (empleado [0] o desempleado [1]). En la Tabla 3 figuran los estadísticos descriptivos para todas nuestras variables independientes.

En la segunda parte de nuestro análisis, donde incluiremos las 15 localidades seleccionadas para las mismas elecciones, utilizaremos un modelo logístico condicional. En él los coeficientes pueden ser interpretados para todos los partidos con independencia del contexto en que se encuentren, dado que los modelos mixtos antes explicados no pueden utilizarse si los contextos difieren en la oferta política, como aquí es el caso. En dichos modelos no pueden incluirse variables específicas de los individuos, ya que de hecho son equivalentes a modelos logísticos con efectos fijos a nivel de individuo. Sin embargo, como proponen Cees van der Eijk y Mark Franklin (1996), es posible pensar que hay partidos que resultan más atractivos para determinados segmentos de la población; se trata de lo que ellos denominan afinidades hacia cada partido. Así, por ejemplo, hay partidos que atraen más a los ciudadanos de derechas, partidos que atraen más a los jóvenes, partidos que atraen más a personas religiosas, etc. Por lo tanto, siguiendo a van der Eijk y Franklin (1996), en esta segunda parte las variables específicas de los individuos (ideología, género, edad, educación y situación laboral) han sido transformadas en probabilidades de que el grupo de población al que pertenece cada persona (por ejemplo, conservadora, mujer, joven, con estudios universitarios y desempleada) vote a cada uno de los partidos ${ }^{5}$. La magnitud de los coeficientes de dichas variables en los modelos puede ahora interpretarse como el efecto de cada variable en la probabilidad de votar a un partido cualquiera (por ejemplo, hasta qué punto estar parado o no afecta a la probabilidad de elegir un partido en lugar de otro).

Como en la primera parte del análisis, en estos modelos centraremos nuestra atención en el efecto de las variables que miden la valoración de cada uno de los candidatos, así como la posición ideológica de los votantes. En sucesivos modelos, introduciremos también interacciones entre estas variables y el tamaño del municipio (medido como el logaritmo del número de votantes en el censo) y la fecha de cada encuesta (medida como una variable categórica con un valor diferente para cada elección que consideramos), lo cual nos permitirá conocer, como planteamos en nuestras hipótesis, si el efecto de la valoración del candidato y de la ideología varía en función de estas dos variables. En estos modelos también incluiremos dos variables específicas para cada combinación entre individuos y partidos: una dicotómica indicando si el partido estaba en la alcaldía en las anteriores elecciones y otra variable dicotómica indicando si ese partido estaba en el Gobierno a nivel nacional (pero no en la alcaldía) en las anteriores elecciones. De esta manera, controlaremos el efecto del incumbency advantage en el voto a nivel local, así como la posible influencia de factores de tipo nacional ${ }^{6}$.

Tabla 3.

Estadísticos descriptivos de las variables independientes

\begin{tabular}{lcccc}
\hline Variables & Media & $\begin{array}{c}\text { Desviación } \\
\text { típica }\end{array}$ & Mínimo & Máximo \\
\hline Edad & 46,84 & 18,13 & 18 & 99 \\
\hline Educación & 3,53 & 1,63 & 0 & 7 \\
\hline Sexo: hombre & 0,505 & 0,499 & 0 & 1 \\
\hline Situación laboral: parado & 0,09 & 0,29 & 1 & 10 \\
\hline Ideología & 4,67 & 1,86 & 0 & 10 \\
\hline Valoración del candidato & 4,504 & 2,58 & 54.160 & 2.404 .697 \\
\hline Censo electoral & $859.974,4$ & $714.638,1$ & 10 \\
\hline
\end{tabular}




\section{Resultados}

\section{En cinco grandes ciudades}

Presentaremos primero el análisis del voto municipal para las cinco grandes ciudades seleccionadas en función del ya mencionado criterio de disponibilidad en el banco de datos del CIS. Para cada ciudad solo hemos tenido en cuenta el voto a los partidos con representación en el ayuntamiento. Esta decisión excluye a todos los entrevistados que hayan votado por partidos que carezcan de concejales (lo que supone un reducido número de casos). Nuestra primera hipótesis afirma el impacto positivo y significativo de la valoración de los candidatos sobre la probabilidad de votar a un determinado partido. Su comprobación está recogida en el Gráfico 1 para cada una de las cinco ciudades seleccionadas. En él se muestra el coeficiente estimado de la valoración de cada candidato en la probabilidad de votar por ese partido. Según puede observarse, el impacto de la valoración del líder o candidato en la probabilidad de votar por alguno de los partidos en todas y cada una de las ciudades y elecciones analizadas resulta altamente significativo. Debido a las características de la técnica estadística utilizada, asumimos que la probabilidad de que la valoración del líder afecte al voto es idéntica para todos los partidos. De ahí el especial interés de que ese efecto se mantenga pese a controlar por el efecto de la ideología en el voto a cada par de partidos (como se detalla en las tablas A1-A5 del apéndice a este artículo). Aunque la variable ideológica deja de ser significativa para algunos partidos en ciertas ciudades y elecciones, el efecto de la valoración del candidato se mantiene constante para todos los casos.

\section{Gráfico 1.}

Efecto de la valoración del candidato sobre la probabilidad predicha de votar a un partido determinado en cinco grandes ciudades, 1999-2011a

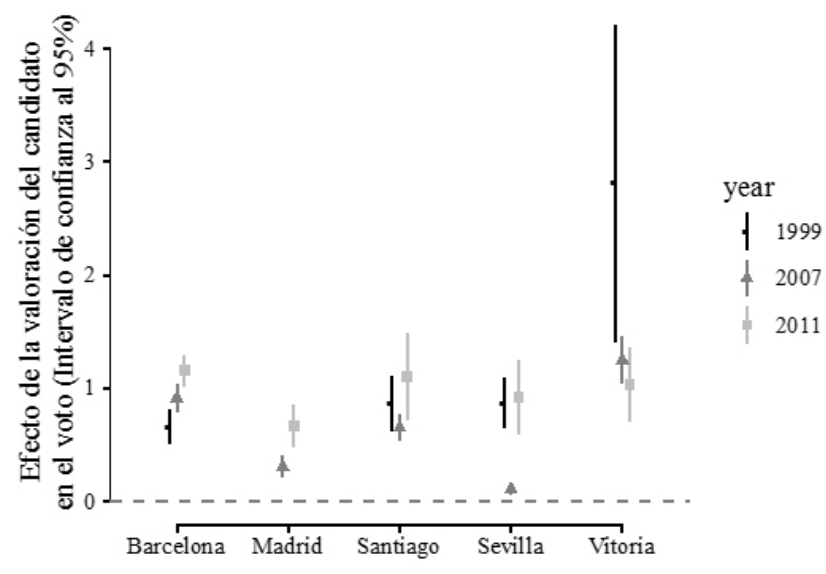

a El Gráfico muestra los coeficientes de la variable relativa a la valoración de cada candidato de acuerdo a los modelos presentados en las tablas A1-A5, recogidas en el Apéndice.
En cuanto a la influencia de las variables específicas de los entrevistados, debe mencionarse que la escasa significatividad de algunas de ellas puede estar ocasionada por el reducido número de observaciones en algunos grupos, lo que debilita los resultados de los estimadores para estas variables y diluye el impacto en el voto de la educación o de la ideología. No ocurre así, sin embargo, con la valoración del candidato, que cuenta con un número de observaciones agrupadas lo suficientemente grande como para comprobar con holgura la validez de nuestra primera hipótesis.

\section{En 15 ciudades}

Procederemos ahora a la segunda parte de nuestro análisis empírico. Tiene dos objetivos. El primero es comprobar si la valoración del candidato municipal en las 15 ciudades seleccionadas sigue mostrando un efecto significativo sobre el voto cuando controlamos por un mayor número de factores y utilizamos datos sobre todos los posibles partidos para los que existe valoración de los candidatos en las encuestas del CIS. Y el segundo consiste en demostrar que la magnitud de ese efecto depende de dos variables contextuales como son el tamaño del municipio y el año de la elección. Los resultados de los distintos modelos se encuentran en la Tabla 4 (modelos sin interacciones) y en las Tablas 5 y 6 (modelos con ellas). Los resultados de la Tabla 4 confirman lo que ya obtuvimos en nuestra muestra de las cinco grandes ciudades: como se recoge en el modelo 1, a mejor valoración del candidato municipal, mayor es la probabilidad de votar por su partido. Este efecto continúa siendo significativo a pesar de considerar en el modelo 2 un mayor número de controles. No obstante, el coeficiente de la valoración del líder es en ellos menor que para la muestra de las cinco grandes ciudades. Ello se debe a que en estos modelos hemos podido introducir un mayor número de variables, una posibilidad de la que antes carecíamos en algunas ocasiones por el limitado número de casos. Este mayor número de variables absorbe buena parte de la fuerza de los coeficientes de la valoración del líder municipal.

Pasemos ahora a analizar las hipótesis $\mathrm{H}_{2 \mathrm{a}} \mathrm{y} \mathrm{H}_{2 \mathrm{~b}}$. Para comprobar si la valoración de los líderes tiene una mayor relevancia en localidades pequeñas, en los modelos 1 y 3 de la Tabla 5 hemos interaccionado esta variable con el censo electoral municipal a escala logarítmica ${ }^{7}$. En general, una mejor valoración del líder local de un partido aumenta la probabilidad de elegir dicho partido sobre los demás; pero este efecto parece disminuir conforme aumenta el tamaño de la localidad, al menos en nuestra muestra de $15 \mathrm{mu}$ nicipios. En cambio, sucede lo contrario en relación con la ideología: los modelos 2 y 3 demuestran que el denominado voto ideológico es más importante en municipios grandes. Así pues, tenemos evidencia empírica para sostener las hipótesis $\mathrm{H}_{2 a} \mathrm{y}_{2 b}{ }^{8}$. 
Tabla 4.

El impacto de los candidatos en el voto en 15 ciudades, 1999, 2007 y 2011a

\begin{tabular}{|c|c|c|}
\hline Variables & Modelo 1 & Modelo 2 \\
\hline \multirow{2}{*}{ Valoración del candidato } & $0,346^{* * *}$ & $0,337^{* * *}$ \\
\hline & $(0,010)$ & $(0,0099)$ \\
\hline \multirow{2}{*}{ Partido en la alcaldía t-1 } & & $0,126^{\star \star *}$ \\
\hline & & $(0,040)$ \\
\hline \multirow{2}{*}{ Partido en el gobierno, pero no en la alcaldía t-1 } & & $-0,617^{* \star *}$ \\
\hline & & $(0,063)$ \\
\hline \multirow{2}{*}{ Ideología } & $0,778^{* * *}$ & $0,776^{\star \star *}$ \\
\hline & $(0,022)$ & $(0,022)$ \\
\hline \multirow{2}{*}{ Hombre } & 0,024 & 0,022 \\
\hline & $(0,018)$ & $(0,018)$ \\
\hline \multirow{2}{*}{ Edad } & 0,014 & 0,027 \\
\hline & $(0,025)$ & $(0,026)$ \\
\hline \multirow{2}{*}{ Educación } & $0,146^{\star \star *}$ & $0,166^{* * *}$ \\
\hline & $(0,019)$ & $(0,019)$ \\
\hline \multirow{2}{*}{ Parado } & $0,146^{\star \star \star}$ & $0,167^{* * *}$ \\
\hline & $(0,024)$ & $(0,025)$ \\
\hline Individuos x Partidos & 22.386 & 22.386 \\
\hline $\mathrm{N}$ Individuos & 6.540 & 6.540 \\
\hline Logaritmo de Verosimilitud & $-4.827,6161$ & $-4.751,0407$ \\
\hline
\end{tabular}

Tabla 5.

El impacto de los candidatos en el voto en 15 ciudades, 1999, 2007 y 2011 (modelos interaccionando con censo)a

\begin{tabular}{|c|c|c|c|}
\hline Variables & Modelo 1 & Modelo 2 & Modelo 3 \\
\hline \multirow{2}{*}{ Valoración del candidato } & $0,828^{* * *}$ & $0,349^{* * *}$ & $0,837^{* * *}$ \\
\hline & $(0,104)$ & $(0,010)$ & $(0,104)$ \\
\hline \multirow{2}{*}{ Partido en la alcaldía t-1 } & $0,159^{* * *}$ & $3,242^{* * *}$ & $0,159^{* * *}$ \\
\hline & $(0,041)$ & $(0,451)$ & $(0,041)$ \\
\hline \multirow{2}{*}{ Partido en el gobierno, pero no en la alcaldía t-1 } & $-0,600^{* * *}$ & $-1,573^{* *}$ & $-0,591^{* * *}$ \\
\hline & $(0,063)$ & $(0,773)$ & $(0,063)$ \\
\hline \multirow{2}{*}{ Ideología } & $0,776^{* * *}$ & $0,783^{* * *}$ & $-0,0001$ \\
\hline & $(0,022)$ & $(0,022)$ & $(0,120)$ \\
\hline \multirow{2}{*}{ Valoración x (In) Censo } & $-0,037^{* * *}$ & & $-0,0380^{* \star *}$ \\
\hline & $(0,008)$ & & $(0,008)$ \\
\hline \multirow{2}{*}{ Ideología x (In) Censo } & & $0,055^{* * *}$ & $0,028^{* * *}$ \\
\hline & & $(0,019)$ & $(0,009)$ \\
\hline \multirow{2}{*}{ Hombre } & 0,021 & 0,023 & 0,009 \\
\hline & $(0,018)$ & $(0,018)$ & $(0,008)$ \\
\hline \multirow{2}{*}{ Edad } & 0,028 & 0,036 & 0,014 \\
\hline & $(0,026)$ & $(0,026)$ & $(0,012)$ \\
\hline \multirow{2}{*}{ Educación } & $0,168^{* * *}$ & $0,168^{* \star *}$ & $0,082^{* * *}$ \\
\hline & $(0,019)$ & $(0,019)$ & $(0,009)$ \\
\hline \multirow{2}{*}{ Parado } & $0,170^{* * *}$ & $0,165^{\star * *}$ & $0,082^{* * *}$ \\
\hline & $(0,025)$ & $(0,025)$ & $(0,012)$ \\
\hline Individuos x Partidos & 22.386 & 22.386 & 22.386 \\
\hline $\mathrm{N}$ Individuos & 6.540 & 6.540 & 6.540 \\
\hline Logaritmo de Verosimilitud & $-4.739,44$ & $-4.719,55$ & $-4.734,87$ \\
\hline
\end{tabular}


También hemos planteado como hipótesis que el efecto de nuestros principales factores explicativos podría cambiar a lo largo del tiempo. La comprobación de su validez se encuentra en los modelos de la Tabla 6, que recogen la interacción de estas variables con el año de la elección. Como puede comprobarse, la única interacción que resulta significativa es la relativa a la valoración del candidato, una variable que adquiere mayor poder explicativo a medida que pasa el tiempo. Por lo tanto, existe cierta evidencia empírica acerca de la creciente personalización del voto en las elecciones municipales en España. El efecto de la ideología, por el contrario, parece mantenerse estable a lo largo del tiempo: la interacción no resulta significativa. Sin embargo, la relevancia de las interacciones en regresiones logísticas no puede apreciarse atendiendo exclusivamente a la significatividad de los coeficientes, dado que la interacción puede no ser significativa para algunos valores de las variables que la componen, pero sí para otros. Como comentaremos más adelante, el cálculo de los efectos marginales permite apreciar que el efecto de la ideología ha cambiado significativamente, pero solo en 2011. Por lo demás, los resultados no cambian sustantivamente al introducir todas las interacciones a la vez en el modelo 3. En lo que se refiere a las variables de control, todas las especificaciones parecen apuntar a que solo la situación laboral del entrevistado y su nivel educativo afectan significativamente a la probabilidad de votar a los distintos partidos en las elecciones municipales; ni el sexo ni la edad alcanzan a tener un efecto estadísticamente significativo. Por último, los datos apuntan al beneficio electoral del que disfrutan los partidos que forman parte del gobierno municipal, pero solo si ocupan la alcaldía.

Para examinar la magnitud de los efectos estimados, el Gráfico 2 muestra el impacto de la valoración de los candidatos y de la ideología sobre las probabilidades predichas de votar a un partido determinado conforme varían el tamaño de la localidad y el año de la elección ${ }^{9}$. Como ilustra el gráfico superior izquierdo, cada punto adicional en la valoración del candidato hace aumentar la probabilidad de votar por su partido en aproximadamente 5 puntos porcentuales en la localidad de menor tamaño considerada (Melilla en 2011, con 54.160 electores). Este efecto disminuye según el número de habitantes aumenta hasta poco más de 4 puntos en el máximo muestral (Madrid en 2011, con 2.404.697 electores). El resultado es el opuesto al de la magnitud del efecto de la ideología, que aumenta en paralelo al tamaño de la población: cada punto adicional de afinidad ideológica aumenta en 3 puntos porcentuales la probabilidad

Tabla 6.

El impacto de los candidatos en el voto en 15 ciudades, 1999, 2007 y 2011 (modelos interaccionando con elección)a

\begin{tabular}{|c|c|c|c|}
\hline Variables & Modelo 1 & Modelo 2 & Modelo 3 \\
\hline \multirow{2}{*}{ Valoración del candidato } & $0,137^{* * *}$ & $0,337^{* * *}$ & $0,232^{\star * *}$ \\
\hline & $(0,032)$ & $(0,010)$ & $(0,018)$ \\
\hline \multirow{2}{*}{ Partido en la alcaldía t-1 } & $0,138^{* * *}$ & $0,126^{\star * *}$ & $0,139^{* * *}$ \\
\hline & $(0,041)$ & $(0,040)$ & $(0,041)$ \\
\hline \multirow{2}{*}{ Partido en el gobierno, pero no en la alcaldía t- 1} & $-0,613^{* \star *}$ & $-0,618^{* * *}$ & $-0,613^{\star * *}$ \\
\hline & $(0,063)$ & $(0,063)$ & $(0,063)$ \\
\hline \multirow{2}{*}{ Ideología } & $0,781^{* * *}$ & $0,745^{\star \star \star}$ & $0,372^{\star * *}$ \\
\hline & $(0,022)$ & $(0,0584)$ & $(0,016)$ \\
\hline \multirow{2}{*}{ Valoración x Elección } & $0,096^{* * *}$ & & $0,096^{* * *}$ \\
\hline & $(0,014)$ & & $(0,014)$ \\
\hline \multirow{2}{*}{ Ideología x Elección } & & 0,015 & $-0,004$ \\
\hline & & $(0,027)$ & $(0,013)$ \\
\hline \multirow{2}{*}{ Hombre } & 0,019 & 0,022 & 0,009 \\
\hline & $(0,018)$ & $(0,018)$ & $(0,008)$ \\
\hline \multirow{2}{*}{ Edad } & 0,0258 & 0,027 & 0,012 \\
\hline & $(0,026)$ & $(0,026)$ & $(0,012)$ \\
\hline \multirow{2}{*}{ Educación } & $0,168^{* \star *}$ & $0,166^{\star \star \star}$ & $0,081^{* * *}$ \\
\hline & $(0,019)$ & $(0,019)$ & $(0,009)$ \\
\hline \multirow{2}{*}{ Parado } & $0,167^{* \star *}$ & $0,166^{\star * *}$ & $0,082^{* * *}$ \\
\hline & $(0,025)$ & $(0,025)$ & $(0,012)$ \\
\hline Individuos $\times$ Partidos & 22.386 & 22.386 & 22.386 \\
\hline $\mathrm{N}$ Individuos & 6.540 & 6.540 & 6.540 \\
\hline Logaritmo de Verosimilitud & $-4.728,59$ & $-4.750,87$ & $-4.728,54$ \\
\hline
\end{tabular}

a Logit condicional; la variable dependiente es votar a un partido determinado. Los niveles de significación estadística son los siguientes: ${ }^{* *} p<0,01,{ }^{* *} p<0,05$, * $p<0,1$; entre paréntesis, errores típicos. La variable de la valoración del líder va de 0 a 10; las del partido del alcalde, partido en el gobierno de coalición y partido votado en anteriores generales, de 0 a 1 ; y las de ideología, sexo, edad, nivel educativo y situación laboral son coeficientes semi-estandarizados. La de la elección es $0=1999,1=2007$ y $2=2011$. 
de votar por esa formación en el mínimo muestral hasta llegar a 6,5 puntos en el máximo muestral.

Los dos componentes inferiores del Gráfico 2 ilustran a su vez cómo el cambio a lo largo del tiempo en el efecto de la valoración del candidato sobre la probabilidad predicha de votar a su partido es menor que el registrado en la magnitud del voto ideológico. Así, mientras que en el caso del primero dicha probabilidad pasa de poco menos de un 4 por ciento en 1999 a poco más de un 5 por ciento en 2011, el efecto de la ideología sobre esa misma probabilidad disminuye de poco más del 6 por ciento a aproximadamente un 4 por ciento entre esos mismos años. Como señalamos con anterioridad, el efecto de la ideología no es estadísticamente diferente para 2007 (respecto a 1999), pero sí para 2011 al ser los intervalos de confianza para ese último año los únicos que no se solapan claramente con los relativos a ese efecto en elecciones anteriores. Como decíamos anteriormente, la imposibilidad de analizar más puntos en el tiempo no nos permite afirmar con total seguridad que exista una creciente personalización del comportamiento electoral de los españoles a nivel local ya que bien podría ser que el efecto estimado para las elecciones de 2011 pudiera deberse a razones de tipo contextual (por ejemplo, la crisis económica).

\section{Conclusiones}

El análisis del comportamiento electoral a nivel municipal es un campo escasamente investigado hasta el momento por la ciencia política. Lo es en buena parte de las democracias occidentales, y lo es también en España. La consideración del nivel local como una arena gubernamental secundaria, con competencias más administrativas que políticas y con unos recursos mucho más limitados que las comunidades autónomas o que por supuesto el gobierno central, ha convertido a las elecciones locales en un objeto de estudio poco frecuentado. $Y$ a ello deben añadirse las notables dificultades metodológicas que presenta el análisis empírico del comportamiento electoral en la galaxia de municipios, como fue gráficamente caracterizada por Joan Botella (1992), dada la dificultad de obtener datos a nivel agregado, y, aún más, individual, y la heterogeneidad de los subsistemas locales de partidos. El que quizás sea el estudio más completo sobre el comportamiento electoral local, escrito por Irene Delgado (1997) hace ya algún tiempo, atestigua estas dificultades.

Pese a todo ello, los ayuntamientos han adquirido a lo largo de la última década una importancia creciente en muchos aspectos que van desde la provisión

\section{Gráfico 2.}

Efecto de la valoración del candidato y de la ideología sobre la probabilidad predicha de votar a un partido determinado conforme aumenta el censo y el año de la elección, 1999, 2007 y 2011a.
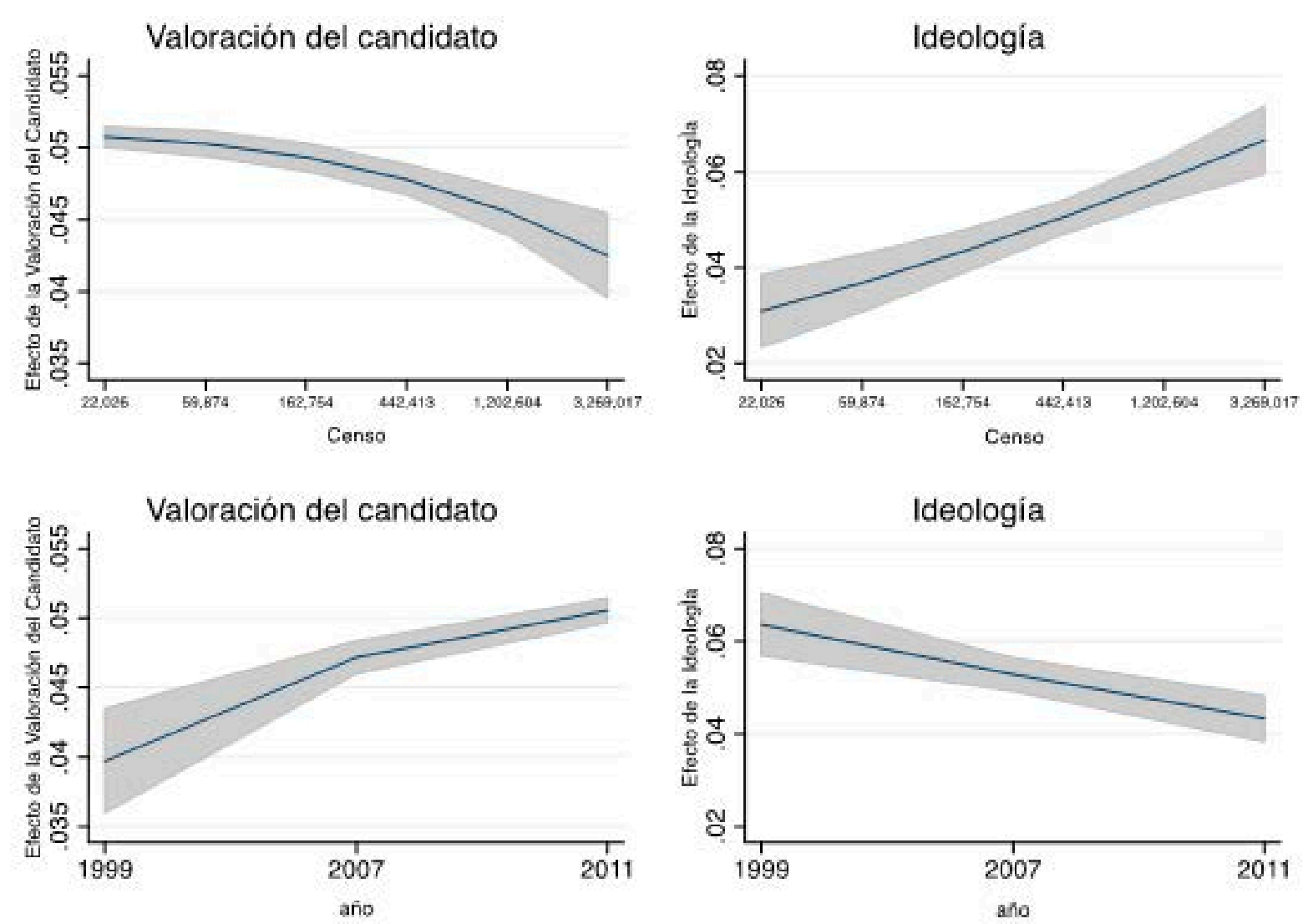

a El Gráfico muestra los efectos marginales medios calculados de acuerdo con los modelos 3 de las Tablas 5 y 6 , estimados usando las medias marginales de todas las demás variables (Mood 2010). 
de servicios públicos al protagonismo en numerosos casos de corrupción política. La mayor relevancia presupuestaria de las Administraciones locales, particularmente observable en las capitales de provincia, ha contribuido a su "repolitización" y a un mayor "localismo" de los Gobiernos municipales (Brugué y Gomà 1998). Aunque Jordi Capo (1991) señalara con ocasión de los primeros comicios que se trataban de elecciones municipales, pero no locales, en el sentido de que la campaña electoral y la competición partidista adoptaron muy pronto pautas nacionales comunes, las características específicamente locales desempeñan papeles cada vez más destacables. Y, como esperamos haber demostrado en este artículo, la personalización del voto es, sin duda, uno de sus mejores ejemplos. De ahí que la comprensión de los factores que explican la decisión electoral a nivel local resulte particularmente necesaria.

A nivel metodológico, este artículo ha puesto en evidencia muchas de las dificultades inherentes al estudio de las elecciones municipales. Aun así, creemos que nuestro trabajo representa un avance considerable en este ámbito dado que (a) nuestro período de análisis, que cubre elecciones celebradas entre 1999 y 2011, es notablemente amplio; (b) hemos podido utilizar sistemáticamente datos individuales para analizar el comportamiento electoral a nivel local; y (c) nuestros modelos han combinado datos individuales con características contextuales de cada municipio, lo que nos ha permitido estimar el efecto de variables a ambos niveles, así como su interacción.

Hemos podido complementar el análisis llevado a cabo para una amplia muestra de municipios en el período 1999-2011 con otro más reducido, pero de mayor profundidad. Así, en la primera parte de la sección empírica de este artículo hemos restringido nuestro estudio a cinco grandes ciudades (Barcelona, Madrid, Santiago de Compostela, Sevilla y Vitoria) para las elecciones de 1999, 2007 y 2011. Estos datos nos han permitido contar con muestras de mayor tamaño y, sobre todo, disponer de indicadores de la valoración de los diferentes candidatos, que a su vez nos han facilitado el examen del impacto de sus rasgos personales en la decisión individual de voto. Hemos podido comprobar así que el efecto del candidato persiste incluso tras controlar por otros factores individuales de tipo sociodemográfico como el sexo, la educación, la situación laboral o la edad del votante; y también por factores de tipo político, como su ideología. Ello sugiere que algunos de los factores que tienen la máxima importancia en las elecciones generales desempeñan también un papel sumamente relevante en las elecciones municipales, normalmente consideradas un escalón inferior en la jerarquía que todos los votantes se hacen de los diferentes tipos de comicios. Y hemos podido asimismo ratificar que la magnitud de la personalización del voto en las elecciones municipales en España se ve modificada por el tamaño del municipio y el paso del tiempo. Dicho esto, nos apresuramos a añadir que futuras investigaciones deberán abordar el tema de la heterogeneidad de los efectos a través de las características de los partidos. Será posible entonces comprobar en qué medida el efecto de la valoración de los candidatos municipales varíe en función de la ideología o el tamaño del partido, o de si el partido se encontraba previamente en la alcaldía.

En fin, hemos demostrado también que los rasgos personales de cada candidato, cifrados en la evaluación que los votantes hacen de ellos, pueden asimismo modificar el sentido del voto de los habitantes de cada municipio. Esta fuente de heterogeneidad descalifica las simplificaciones de quienes tratan las elecciones municipales como un mero reflejo de lo que sucede en la arena nacional o de quienes solo las consideran como unas primarias de las próximas generales. Contra ambas deformaciones, las elecciones locales españolas constituyen un objeto de estudio que permite seguir discutiendo problemas irresueltos en el campo de la representación democrática y cuyo análisis empírico facilita un conocimiento más acabado de los factores explicativos que concurren en la decisión del voto. Una tarea que resulta especialmente importante en momentos en los que los vientos de cambio surgidos tras las elecciones europeas de 2014 y las autonómicas, municipales y generales de 2015 pueden modificar el peso de componentes sustantivos de la explicación electoral en los comicios locales; o pueden también mantenerlos pese a un nuevo escenario político mucho más competitivo y fragmentado. Según creemos, esta circunstancia proporciona a nuestro artículo un motivo adicional de relevancia.

\section{Agradecimientos}

Este artículo ha podido escribirse tras la concesión a los autores de una Ayuda de Investigación del Centro de Investigaciones Sociológicas (CIS) en 2011. Queremos agradecer al CIS la oportunidad que nos brindó para trabajar sobre un tema tan interesante como poco frecuentado; al personal de su Banco de Datos, su colaboración en la desanonimización parcial de muchas de las encuestas utilizadas en este trabajo; a Jaume Magre, sus valiosos comentarios, y a Paz Fernández y a Luis Martínez, de la Biblioteca del Centro de Estudios Avanzados en Ciencias Sociales (CEACS), del Instituto Juan March, su ayuda para la localización de numerosas bases de datos que han resultado sumamente útiles. Los autores quieren también reconocer el apoyo proporcionado por el Proyecto Comportamiento Electoral y Políticas Públicas (CSO2013-40870-R), concedido por el Ministerio de Economía y Competitividad. 


\section{NotAs}

[1] Este artículo ha podido escribirse tras la concesión a los autores de una Ayuda de Investigación del Centro de Investigaciones Sociológicas (CIS) en 2011. Queremos agradecer al CIS la oportunidad que nos brindó para trabajar sobre un tema tan interesante como poco frecuentado; al personal de su Banco de Datos, su colaboración en la desanonimización parcial de muchas de las encuestas utilizadas en este trabajo; a Jaume Magre, sus valiosos comentarios, y a Paz Fernández y a Luis Martínez, de la Biblioteca del Centro de Estudios Avanzados en Ciencias Sociales (CEACS), del Instituto Juan March, su ayuda para la localización de numerosas bases de datos que han resultado sumamente útiles. Los autores quieren también reconocer el apoyo proporcionado por el Proyecto Comportamiento electoral y políticas públicas (CSO2013-40870-R), concedido por el Ministerio de Economía y Competitividad.

[2] En este artículo utilizaremos de forma indistinta líder y candidato, por un lado, y local y municipal, por el otro.

[3] Idealmente, nos hubiera gustado contar con una muestra de casos que presentaran una mayor variación tanto en lo que se refiere al tamaño de la población como al año de la elección. Lamentablemente, la valoración de candidatos a la alcaldía no estaba disponible ni para municipios más pequeños ni para elecciones anteriores. A pesar de ello, creemos que esta circunstancia, lejos de ser un problema, lo único que podría hacer es introducir sesgos de atenuación en nuestro análisis y, por lo tanto, iría en contra de nuestras hipótesis.

[4] Aunque aquí se recogen los resultados incluyendo a Ceuta y Melilla en los análisis, los resultados permanecen prácticamente inalterados y están disponibles a petición de los interesados cuando se excluyen estas dos ciudades autónomas.

[5] Esta técnica permite incluir características individuales como variables independientes en modelos condicionales convirtiéndolas en variables relativas a cada alternativa. Las afinidades no son más que

\section{RefERencias Bibliográficas}

Aarts, K., A. Blais y H. Schmitt. eds. 2011. Political Leaders and Democratic Elections. Oxford: Oxford University Press.

Barberá, P. 2010. "Voting for Parties or for Candidates? The Trade-Off Between Party and Personal Representation in Spanish Regional and Local Elections". Revista Española de Investigaciones Sociológicas 132: 35-63.

Barreiro, B. e I. Sánchez-Cuenca. 1998. "Análisis del cambio de voto hacia el PSOE en las elecciones de 1993". Revista Española de Investigaciones Sociológicas 82: 191-214. http://dx.doi.org/10.2307/40184056

Bartle, J. e I. Crewe. 2002. "The Impact of Party Leaders in Britain: Strong Assumptions, Weak Evidence”. Pp. 7095 en Leaders' Personalities and the Outcomes of Democratic Elections, editado por A. King. Oxford: Oxford University Press.

Bean, C. 1993. "The Electoral Influence of Party Leader Images in Australia and New Zealand". Comparative Political Studies 26: 111-132. http://dx.doi. org/10.1177/0010414093026001005

Botella, J. 1992. "La galaxia local en el sistema político español". Revista de Estudios Políticos 76: 145-160. una transformación de la variable independiente en las que el valor de la característica individual del entrevistado (por ejemplo, estar desempleado) se sustituye por la probabilidad que los entrevistados que comparten dicha característica tienen de votar a cada partido. Dicha probabilidad se obtiene de una serie de modelos bivariados donde la variable dependiente es la probabilidad de votar al partido $X$ y la variable independiente es la característica individual que nos interese. Los modelos se repiten para cada una de las alternativas. Al ser una mera transformación matemática de la variable independiente, el uso de afinidades no afecta a la validez de los modelos. Para mayor información sobre esta técnica se puede ver van der Eijk y Franklin (1996).

[6] Otras variables podrían ser más adecuadas si el fin es controlar por la influencia de lo que ocurre en la arena nacional, tal y como la valoración de la situación económica en el país o la valoración de la gestión del Gobierno central. Sin embargo, este tipo de preguntas no fueron incluidas de manera sistemática en todas las encuestas que analizamos. Pese a las limitaciones de nuestro análisis, creemos que controlando por el partido en el Gobierno a nivel nacional se captura gran parte de la variación en estas variables.

[7] Estas regresiones no incluyen los términos constitutivos de la interacción de manera explícita debido a que los modelos logísticos condicionales son equivalentes a modelos logísticos con efectos fijos a nivel de individuo (y en nuestro caso, también municipio y elección). Por este motivo, si incluyéramos variables dicotómicas indicando la elección y municipio, esto induciría a multicolinealidad perfecta.

[8] Para resultados en cierta medida similares en algunas elecciones locales de Andalucía, cf. Martínez Fuentes y Ortega (2010b) y Ortega, García Hípola y Trujillo (2013).

[9] Para calcularlas, hemos utilizado los modelos 3 de las Tablas 5 y 6 .

Brettschneider, F. y O. W. Gabriel. 2002. "The Non-personalization of Voting Behavior in Germany". Pp. 127-157 en Leaders' Personalities and the Outcomes of Democratic Elections, editado por A. King. Oxford: Oxford University Press.

Brugué, Q. y R. Gomà. 1998. Gobiernos locales y políticas públicas. Barcelona: Ariel.

Burden, B. y A. Wichowsky. 2010. "Local and National Forces in Congressional Elections". Pp. 453-470 en The Oxford Handbook of American Elections and Political Behavior, editado por J. E. Leighley. Oxford: Oxford University Press. http://dx.doi.org/10.1093/oxfordhb/9780199235476.003.0024

Capo, J. 1991. "Elecciones municipales, pero no locales". Revista Española de Investigaciones Sociológicas 56: 143-164.

Clarke, H. 2000. "Major's Lesser (Not Minor) Effects: Prime Ministerial Approval and Governing Party Support in Britain since 1979". Electoral Studies 19: 255-273. http:// dx.doi.org/10.1016/S0261-3794(99)00051-7

Costa Lobo, M. 2014. "Party and Electoral Leadership". Pp. 362-375 en The Oxford Handbook of Political Leadership, editado por M. Rhodes y P. 't Hart. Oxford: Oxford University Press. 
Costa Lobo, M. y J. Curtice. eds. 2014. Personality Politics? The Role of Leader Evaluations in Democratic Elections. Oxford: Oxford University Press. http://dx.doi. org/10.1093/acprof:oso/9780199660124.001.0001

Criado, I. y G. Martínez Fuentes. 2009. "Liderazgo y comunicación en la era del blogging político: aproximación teórica, evidencia empírica y propuesta analítica". Razón y Palabra 70: 1-24.

Criado, I. y G. Martínez Fuentes. 2010. "Blogging político y personalización de la democracia local en España y Portugal. Evidencias presentes y propuestas de futuro". Estudios de Progreso. Madrid: Fundación Alternativas.

Delgado, I. 1997. El comportamiento electoral municipal español, 1979-1995. Madrid: Centro de Investigaciones Sociológicas.

Delgado, I. 1999. "Resultados electorales y orientación del voto en los comicios municipales de 1995". Revista Española de Investigaciones Sociológicas 86: 247-273.

Delgado, I. 2010. "Elecciones municipales en España. Dimensiones analíticas y aspectos distintivos de ocho procesos electorales (1997-2007)". Política y Sociedad 47: 13-36.

Freire, A. 2005. "Eleições de segunda ordem e ciclos eleitorais no Portugal democrático, 1975-2004". Análise Social 177: 815-846.

Gunther, R., G. Sani y G. Shabad. 1986. El sistema de partidos políticos en España: génesis y evolución. Madrid: Centro de Investigaciones Sociológicas.

Gunther, R. y J. R. Montero. 2001. "The Anchors of Partisanship: A Comparative Analysis of Voting Behaviour in Four Southern European Democracies". Pp. 83-152 en Parties, Politics, and Democracy in the New Southern Europe, editado por P. Nikiforos Diamandouros y R. Gunther. Baltimore: John Hopkins University Press.

Graetz, B. e I. McAllister. 1987. "Party Leaders and Electoral Outcomes in Britain, 1974-1983". Comparative Political Studies 19: 484-507. http://dx.doi. org/10.1177/0010414087019004002

Hazan, R. Y. 1996. "Presidential Parliamentarism: Direct Popular Election of the Prime Minister". Electoral Studies 15: 21-38. http://dx.doi.org/10.1016/02613794(94)00003-4

King, A. 2002. "Conclusions and Implications". Pp. 210222 en Leaders' Personalities and the Outcomes of Democratic Elections, editado por A. King. Oxford: Oxford University Press. http://dx.doi. org/10.1093/0199253137.003.0008

Krebs, T. B. 2014. "Local Campaigns and Elections". Pp. 189211 en The Oxford Handbook of State and Local Governments, editado por D. P. Haider-Merkel. Oxford: Oxford University Press.

Lau, R. R. y D. P. Redlawsk. 2006. How Voters Decide: Information Processing in Election Campaigns. Cambridge: Cambridge University Press. http://dx.doi.org/10.1017/ СBO9780511791048

Lewis, P. 2011. "Size and Local Democracy: Scale Effects in City Politics". PS: Political Science \& Politics 44: 107109. http://dx.doi.org/10.1017/S1049096510001976

López Nieto, L. e I. Delgado. 1994. "Innovación urbana española: ¿una nueva clase política?" Revista de Estudios Políticos 86: 313-344.

Maddens, B. y S. Fiers. 2004. "The Direct PM Election and the Institutional Presidentialisation of Parliamentary Systems". Electoral Studies 23: 769-793. http://dx.doi. org/10.1016/j.electstud.2003.10.006
Manin, B. 1997. The Principles of Representative Government. Cambridge: Cambridge University Press. http:// dx.doi.org/10.1017/СВ09780511659935

Márquez, G. 2007. Política y gobierno local. La formación de gobierno en las entidades locales en España. Madrid: Centro de Estudios Políticos y Constitucionales.

Marschall, M., P. Shah y A. Ruhil. 2011. "The study of local elections". PS: Political Science \& Politics 44(1): 97100. http://dx.doi.org/10.1017/s1049096510001940

Martínez Fuentes, G. 2008. "Local Political Leadership in Spain". Local Government Studies 34: 267-278. http:// dx.doi.org/10.1080/03003930701852336

Martínez Fuentes, G. y C. Ortega. 2010a. "The Political Leadership Factor in the Spanish Local Elections". Lex Localis. Journal of Local Self-Government 8: 147-160.

Martínez Fuentes, G. y C. Ortega. 2010b. "Las elecciones municipales de 2007 en Andalucía. Un estudio del comportamiento electoral de los andaluces". Psicología Política 41: 2-25.

McAllister, I. 2009. "The Personalization of Politics". Pp. 571588 en The Oxford Handbook of Political Behavior, editado por R. J. Dalton y H.-D. Klingemann. Oxford: Oxford University Press.

McFadden, D. 1974. "Conditional Logit Analysis of Qualitative Choice Behavior". Pp. 105-142 en Frontiers in Econometrics, editado por P. Zarembka. Nueva York: Academic Press.

Mood, C. 2010. "Logistic Regression: Why We Cannot Do What We Think We Can Do, and What We Can Do About It". European Sociological Review 26: 67-82. http://dx.doi.org/10.1093/esr/jcp006

Molins, J. M. y S. Pardos. 2005. "Las elecciones municipales de 2003 en Cataluña. El ruido contra la estructura: lo global y lo local". Pp. 91-118 en Política comparada. Entre lo global y lo local, editado por F. Llera y P. Oñate. Madrid: Centro de Investigaciones Sociológicas.

Mughan, A. 1993. "Party Leaders and Presidentialism in the 1992 British Election: A Postwar Perspective". Pp. 193204 en British Elections and Parties Yearbook, editado por D. Denver, P. Norris y C. Rallings. Londres: Harvester Wheatsheaf.

Natera, A. 2001. El liderazgo político en las sociedades democráticas. Madrid: Centro de Estudios Políticos y Constitucionales.

Orriols, L. y S. Lavezzolo. 2008. "El liderazgo de Blair y Aznar hacia el centro político". Revista de Estudios Políticos 142: 69-103.

Ortega, C., G. García Hípola y J. M. Trujillo. 2013. "La influencia de la atmósfera política local sobre la conducta electoral. Un estudio del voto socialista en las elecciones locales andaluzas de 2011". Revista Internacional de Sociología 71: 617-641. http://dx.doi.org/10.3989/ ris.2012.04.16

Poguntke, T. y P. Webb. eds. 2005. The Presidentialization of Politics in Democratic Societies. Oxford: Oxford University Press. http://dx.doi. org/10.1093/0199252017.001.0001

Reif, K. y H. Schmitt. 1980. "Nine Second-Order National Elections - A Conceptual Framework for the Analysis of European Election Results". European Journal of Political Research 8: 3-44. http://dx.doi. org/10.1111/j.1475-6765.1980.tb00737.x

Rico, G. 2007. "'¡No nos falles!' Los candidatos y su peso electoral". Pp. 331-360 en Elecciones generales 2004, editado por J. R. Montero, I. Lago y M. Torcal. Madrid: Centro de Investigaciones Sociológicas. 
Rico, G. 2009. Líderes políticos, opinión pública y comportamiento electoral en España. Madrid: Centro de Investigaciones Sociológicas.

Rico, G. 2011. "El impacto de los líderes en las elecciones de 2008". Pp. 303-330 en Elecciones generales 2008, editado por J. R. Montero e I. Lago. Madrid: Centro de Investigaciones Sociológicas.

Steenbergen, M. R. y M. Lodge. 2003. "Process Matters: Cognitive Models of Candidate Evaluation". Pp. 125-171 en Electoral Democracy, editado por M. M. MacKuen y G. Rabinowitz. Ann Arbor: University of Michigan Press.

Torcal, M., J. R. Montero y R. Gunther. 2003. "Ciudadanos y partidos en el sur de Europa: los sentimientos antipartidistas". Revista Española de Investigaciones Sociológicas 101: 9-48. http://dx.doi.org/10.2307/40184450
Van Biezen, I. y J. Hopkin. 2005. "The Presidentialization of Spanish Democracy: Sources of Prime Ministerial Power in Post Franco Spain". Pp. 107-127 en The Presidentialization of Politics. A Comparative Study of Modern Democracies, editado por T. Poguntke y P. Webb. Oxford: Oxford University Press.

Van der Eijk, C. y M. Franklin. 1996. Choosing Europe? The European Electorate and National Politics in the Face of the Union. Ann Arbor: Michigan University Press. http://dx.doi.org/10.3998/mpub.13603

Vanaclocha, F. J. 1997. "Identidad de los gobiernos locales y reforma electoral". Pp. 275-299 en El sistema político local: un nuevo escenario de gobierno, editado por $\mathrm{C}$. R. Alba y F. J. Vanaclocha. Madrid: Universidad Carlos III, Boletín Oficial del Estado.

PEDRO RIERA SAGRERA es Profesor de Ciencia Política en la Universidad Carlos III de Madrid. Tras licenciarse en Derecho y Ciencias Políticas y de la Administración (Universidad de Barcelona, 2002 y 2003) y obtener su título de Maestro en Ciencias Sociales (Instituto Juan March, 2007), realizó su doctorado en Ciencias Sociales en el Instituto Universitario Europeo de Florencia (2013) y es doctor-miembro del Instituto Juan March. Ha sido profesor en la Universidad de Strathclyde (Glasgow, Reino Unido). Sus principales áreas de investigación son el comportamiento político y la ingeniería electoral.

RAÚL GÓMEZ MARTíNEZ es Profesor de Ciencia Política en la Universidad de Liverpool. Tras licenciarse en Derecho y Ciencias Políticas y de la Administración (Universidad de Murcia, 2002 y 2004), y obtener su título de Maestro en Ciencias Sociales (Instituto Juan March, 2008), realizó su doctorado en Ciencias Sociales en el Instituto Universitario Europeo de Florencia (2012) y es doctor-miembro del Instituto Juan March. Ha sido investigador en la Universidad de Liverpool (Reino Unido) y docente invitado en la universidad de Maastricht (Holanda). Sus principales áreas de investigación son opinión pública, género y política, partidos políticos y comportamiento electoral.

JUAN ANTONIO MAYORAL DÍAZ-ASENSIO es Investigador Posdoctoral en iCourts - Centro de Excelencia para Tribunales Internacionales de la Universidad de Copenhague (Dinamarca). Es licenciado en Derecho, Filosofía y Ciencias Políticas, y obtuvo títulos de Maestría en Ciencias Sociales (Instituto Juan March, 2008) y en Democracia y Gobierno (Universidad Autónoma de Madrid, 2009). Es doctor en Ciencias Políticas y Sociales por el Instituto Universitario Europeo de Florencia (2013) y doctor-miembro del Instituto Juan March. Sus principales áreas de investigación son la política judicial comparada y los procesos de integración legal y judicial.

PABLO BARBERÁ ARAGÜENA es Profesor de Relaciones Internacionales en la Universidad del Sur de California en Los Ángeles (Estados Unidos). Investigador Posdoctoral en la Universidad de Nueva York (Estados Unidos). Tras licenciarse en Ciencias Políticas y de la Administración (Universidad Pompeu Fabra, Barcelona, España) y recibir su título de Maestro en Investigación en Ciencias Políticas y Sociales (Instituto Universitario Europeo, Florencia, Italia), obtuvo su doctorado en Ciencia Política en la Universidad de Nueva York (2015). Sus principales áreas de investigación son el estudio de las redes sociales y el comportamiento electoral.

JOSÉ RAMÓN MONTERO GIBERT es Catedrático de Ciencia Política en la Universidad Autónoma de Madrid y Profesor Asociado de Ciencia Política en el Instituto de Empresa. Es Doctor en Derecho por la Universidad de Santiago de Compostela, y ha enseñado en las de Granada, Santiago, Zaragoza, Cádiz y Complutense de Madrid. Ha sido Profesor de Ciencia Política en el Instituto Juan March, y Visiting Fellow en Harvard University, University of California en Berkeley, Ohio State University, Institut d'Études Politiques de Burdeos, ICSTE-Instituto Universitário de Lisboa, Universidad del Desarrollo de Santiago de Chile y European University Institute e Istituto Italiano di Scienze Umane, ambos en Florencia. Sus principales áreas de investigación son comportamiento electoral, partidos políticos, participación política y actitudes políticas. 


\section{ApÉNDICE}

Tabla A1.

Barcelona: el impacto de los candidatos en el voto, 1999, 2007 y 2011a

\begin{tabular}{|c|c|c|c|c|c|c|}
\hline Variables & Partido & & PP/PSC & ICV/PSC & CiU/PSC & ERC/PSC \\
\hline \multicolumn{7}{|c|}{1999} \\
\hline Valoración del candidato & $\begin{array}{c}0,659^{* * *} \\
(0,078)\end{array}$ & & & & & \\
\hline Ideología & & & $\begin{array}{l}1,373^{* * *} \\
(0,362)\end{array}$ & $\begin{array}{c}-0,563^{* *} \\
(0,223)\end{array}$ & $\begin{array}{c}0,730^{* * *} \\
(0,149)\end{array}$ & $\begin{array}{l}-0,597^{* *} \\
(0,254)\end{array}$ \\
\hline Hombre & & & $\begin{array}{l}-0,169 \\
(0,759)\end{array}$ & $\begin{array}{c}0,192 \\
(0,494) \\
\end{array}$ & $\begin{array}{l}-0,279 \\
(0,357) \\
\end{array}$ & $\begin{array}{l}-0,578 \\
(0,597) \\
\end{array}$ \\
\hline Edad & & & $\begin{array}{l}-0,04 \\
(0,03)\end{array}$ & $\begin{array}{l}-0,01 \\
(0,01)\end{array}$ & $\begin{array}{c}0,011 \\
(0,011)\end{array}$ & $\begin{array}{l}-0,012 \\
(0,021)\end{array}$ \\
\hline Educación & & & $\begin{array}{l}-0,154 \\
(0,321)\end{array}$ & $\begin{array}{l}-0,339^{*} \\
(0,191)\end{array}$ & $\begin{array}{c}0,165 \\
(0,133)\end{array}$ & $\begin{array}{l}0,0246 \\
(0,224)\end{array}$ \\
\hline Parado & & & $\begin{array}{c}1,518 \\
(1,395)\end{array}$ & $\begin{array}{c}0,196 \\
(0,799)\end{array}$ & $\begin{array}{c}0,229 \\
(0,613)\end{array}$ & $\begin{array}{l}-14,14 \\
(588,8)\end{array}$ \\
\hline Constante & & & $\begin{array}{l}-5,203^{* *} \\
(2,513)\end{array}$ & $\begin{array}{l}3,807^{* *} \\
(1,499)\end{array}$ & $\begin{array}{c}-4,452^{* * *} \\
(1,136) \\
\end{array}$ & $\begin{array}{c}2,093 \\
(1,763) \\
\end{array}$ \\
\hline $\mathrm{N}$ & & $\begin{array}{c}1.130 \\
\text { (319 individuos) }\end{array}$ & & & & \\
\hline Logaritmo de Verosimilitud & & $-218,215$ & & & & \\
\hline
\end{tabular}

2007

\begin{tabular}{|c|c|c|c|c|c|}
\hline Valoración del candidato & $\begin{array}{c}0,910^{* * *} \\
(0,063)\end{array}$ & & & & \\
\hline Ideología & & $\begin{array}{c}1,415^{\star \star \star} \\
(0,204) \\
\end{array}$ & $\begin{array}{c}-0,645^{\star * \star} \\
(0,138) \\
\end{array}$ & $\begin{array}{c}1,035^{\star \star *} \\
(0,130)\end{array}$ & $\begin{array}{c}-0,644^{\star \star \star} \\
(0,135) \\
\end{array}$ \\
\hline Hombre & & $\begin{array}{c}0,185 \\
(0,523) \\
\end{array}$ & $\begin{array}{c}-0,400 \\
(0,301) \\
\end{array}$ & $\begin{array}{c}-0,278 \\
(0,290) \\
\end{array}$ & $\begin{array}{l}-0,187 \\
(0,307) \\
\end{array}$ \\
\hline Edad & & $\begin{array}{c}0,001 \\
(0,0164) \\
\end{array}$ & $\begin{array}{r}-0,035^{\star \star *} \\
(0,0105) \\
\end{array}$ & $\begin{array}{c}0,0182^{* *} \\
(0,009)\end{array}$ & $\begin{array}{l}-0,003 \\
(0,010) \\
\end{array}$ \\
\hline Educación & & $\begin{array}{c}0,006 \\
(0,182) \\
\end{array}$ & $\begin{array}{l}0,189^{*} \\
(0,108)\end{array}$ & $\begin{array}{l}0,272^{* * *} \\
(0,0971)\end{array}$ & $\begin{array}{l}0,230^{\star *} \\
(0,108)\end{array}$ \\
\hline Parado & & $\begin{array}{c}-1,694 \\
(1,595) \\
\end{array}$ & $\begin{array}{l}-0,089 \\
(0,523) \\
\end{array}$ & $\begin{array}{c}-0,718 \\
(0,865) \\
\end{array}$ & $\begin{array}{c}0,156 \\
(0,526) \\
\end{array}$ \\
\hline Constante & & $\begin{array}{c}-8,008^{\star \star *} \\
(1,770)\end{array}$ & $\begin{array}{l}2,195^{\star *} \\
(0,893)\end{array}$ & $\begin{array}{c}-6,620^{\star \star *} \\
(1,002)\end{array}$ & $\begin{array}{c}0,614 \\
(0,888)\end{array}$ \\
\hline
\end{tabular}

$\mathrm{N}$

Logaritmo de Verosimilitud



a Logit condicional; la variable dependiente es el voto a un partido determinado. Los niveles de significación estadística son los siguientes: ${ }^{* * *} p<0,01,{ }^{* *}$ $p<0,05,{ }^{*} p<0,1$; entre paréntesis, errores típicos. 
Tabla A2.

Madrid: el impacto de los candidatos en el voto, 2007 y 2011a

\begin{tabular}{|c|c|c|c|c|c|}
\hline Variables & Partido & & PP/PSOE & IU/PSOE & UPyD/PSOE \\
\hline & \multicolumn{5}{|c|}{2007} \\
\hline \multirow{2}{*}{ Valoración del candidato } & $0,302^{* * *}$ & & & & \\
\hline & $(0,051)$ & & & & \\
\hline \multirow{2}{*}{ Ideología } & & & $0,479^{* * *}$ & $-0,074$ & \\
\hline & & & $(0,109)$ & $(0,139)$ & \\
\hline \multirow{2}{*}{ Edad } & & & $0,008^{* *}$ & $-0,004$ & \\
\hline & & & $(0,014)$ & $(0,017)$ & \\
\hline \multirow{2}{*}{ Educación } & & & 0,214 & 0,164 & \\
\hline & & & $(0,145)$ & $(0,167)$ & \\
\hline \multirow{2}{*}{ Parado } & & & 0,215 & $-0,049$ & \\
\hline & & & $(0,712)$ & $(0,866)$ & \\
\hline \multirow{2}{*}{ Constante } & & & $-3,865^{\star \star *}$ & $-2,024$ & \\
\hline & & & $(1,239)$ & $(1,387)$ & \\
\hline $\mathrm{N}$ & & $\begin{array}{c}900 \\
\text { (343 individuos) }\end{array}$ & & & \\
\hline \multirow[t]{2}{*}{ Logaritmo de Verosimilitud } & & $-166,409$ & & & \\
\hline & & 2011 & & & \\
\hline \multirow{2}{*}{ Valoración del candidato } & $0,665^{\star \star *}$ & & & & \\
\hline & $(0,099)$ & & & & \\
\hline \multirow{2}{*}{ Ideología } & & & $1,488^{\star \star \star}$ & $-0,698^{* *}$ & $1,048^{* * *}$ \\
\hline & & & $(0,245)$ & $(0,338)$ & $(0,355)$ \\
\hline \multirow{2}{*}{ Edad } & & & 0,030 & $-0,001$ & 0,048 \\
\hline & & & $(0,019)$ & $(0,022)$ & $(0,068)$ \\
\hline \multirow{2}{*}{ Educación } & & & 0,237 & $0,364^{*}$ & 0,790 \\
\hline & & & $(0,192)$ & $(0,207)$ & $(0,659)$ \\
\hline \multirow{2}{*}{ Parado } & & & 1,016 & $-1,924$ & $3,246^{* *}$ \\
\hline & & & $(0,795)$ & $(1,192)$ & $(1,653)$ \\
\hline \multirow{2}{*}{ Constante } & & & $-9,458^{\star * \star}$ & 0,0475 & $-12,78^{\star \star \star}$ \\
\hline & & & $(1,918)$ & $(1,897)$ & $(4,439)$ \\
\hline $\mathrm{N}$ & & $\begin{array}{c}836 \\
\text { (327 individuos) }\end{array}$ & & & \\
\hline Logaritmo de Verosimilitud & & $-89,290$ & & & \\
\hline
\end{tabular}

a Logit condicional; la variable dependiente es el voto a un partido determinado. Los niveles de significación estadística son los siguientes: *** $\mathrm{p}<0,01$, ** $p<0,05,{ }^{*} p<0,1$; entre paréntesis, errores típicos.

Tabla A3.

Estadísticos descriptivos de las variables independientes

\begin{tabular}{|c|c|c|c|c|}
\hline Variables & Media & $\begin{array}{c}\text { Desviación } \\
\text { típica }\end{array}$ & Mínimo & Máximo \\
\hline Edad & 46,84 & 18,13 & 18 & 99 \\
\hline Educación & 3,53 & 1,63 & 0 & 7 \\
\hline Sexo: hombre & 0,505 & 0,499 & 0 & 1 \\
\hline Situación laboral: parado & 0,09 & 0,29 & 0 & 1 \\
\hline Ideología & 4,67 & 1,86 & 1 & 10 \\
\hline Valoración del candidato & 4,504 & 2,58 & 0 & 10 \\
\hline Censo electoral & $859.974,4$ & $714.638,1$ & 54.160 & 2.404 .697 \\
\hline
\end{tabular}


Tabla A4.

Sevilla: el impacto de los candidatos en el voto, 1999, 2007 y 2011

\begin{tabular}{|c|c|c|c|c|}
\hline Variables & Partido & PPIPSOE & IU/PSOE & PA/PSOE \\
\hline \multicolumn{5}{|c|}{1999} \\
\hline \multirow{2}{*}{ Valoración del candidato } & $0,868^{* * *}$ & & & \\
\hline & $(0,115)$ & & & \\
\hline \multirow{2}{*}{ Ideología } & & $1,288^{* * *}$ & $-0,286$ & 0,430 \\
\hline & & $(0,318)$ & $(0,385)$ & $(0,287)$ \\
\hline \multirow{2}{*}{ Hombre } & & $-0,230$ & 0,380 & $-0,698$ \\
\hline & & $(0,689)$ & $(1,027)$ & $(0,710)$ \\
\hline \multirow{2}{*}{ Edad } & & $-0,019$ & $-0,008$ & $-0,041^{*}$ \\
\hline & & $(0,022)$ & $(0,034)$ & $(0,023)$ \\
\hline \multirow{2}{*}{ Educación } & & $0,704^{\star * *}$ & $0,592^{*}$ & $0,534^{* *}$ \\
\hline & & $(0,246)$ & $(0,320)$ & $(0,250)$ \\
\hline \multirow{2}{*}{ Parado } & & $-1,891$ & $-14,12$ & $-1,515$ \\
\hline & & $(1,152)$ & $(806,1)$ & $(1,090)$ \\
\hline \multirow{2}{*}{ Constante } & & $-8,355^{* * *}$ & $-2,342$ & $-2,949$ \\
\hline & & $(2,278)$ & $(2,469)$ & $(1,959)$ \\
\hline $\mathrm{N}$ & & iduos) & & \\
\hline \multirow[t]{2}{*}{ Logaritmo de Verosimilitud } & & & & \\
\hline & & & & \\
\hline \multirow{2}{*}{ Valoración del candidato } & $0,105^{\star * *}$ & & & \\
\hline & $(0,028)$ & & & \\
\hline \multirow{2}{*}{ Ideología } & & 0,0517 & $-0,536^{* * *}$ & \\
\hline & & $(0,068)$ & $(0,125)$ & \\
\hline \multirow{2}{*}{ Hombre } & & $0,358^{*}$ & 0,235 & \\
\hline & & $(0,204)$ & $(0,371)$ & \\
\hline \multirow{2}{*}{ Edad } & & 0,004 & $-0,031^{* *}$ & \\
\hline & & $(0,007)$ & $(0,013)$ & \\
\hline \multirow{2}{*}{ Educación } & & $-0,0913$ & 0,112 & \\
\hline & & $(0,072)$ & $(0,130)$ & \\
\hline \multirow{2}{*}{ Parado } & & 0,146 & 0,248 & \\
\hline & & $(0,575)$ & $(0,657)$ & \\
\hline \multirow{2}{*}{ Constante } & & 0,0701 & $1,680^{*}$ & \\
\hline & & $(0,582)$ & $(0,979)$ & \\
\hline
\end{tabular}

$\mathrm{N}$

Logaritmo de Verosimilitud

(484 individuos) $-378,261$

\begin{tabular}{lccc}
\hline & \multicolumn{2}{c}{$\mathbf{2 0 1 1}$} & \\
\hline Valoración del candidato & $0,916^{* * *}$ & & \\
\hline \multirow{2}{*}{ Ideología } & $(0,170)$ & $1,964^{* * *}$ & $-0,169$ \\
& & $(0,532)$ & $(0,323)$ \\
\hline \multirow{2}{*}{ Hombre } & 0,628 & $-1,064$ \\
& & $(0,939)$ & $(0,893)$ \\
\hline \multirow{2}{*}{ Edad } & $-0,018$ & $-0,098^{* *}$ \\
& & $(0,036)$ & $(0,045)$ \\
\hline \multirow{2}{*}{ Educación } & 0,323 & 0,361 \\
Parado & $(0,314)$ & $(0,308)$ \\
\hline \multirow{2}{*}{ Constante } & $-1,766$ & $-1,057$ \\
& & $(1,303)$ & $(1,080)$ \\
\hline \multirow{2}{*}{$\mathrm{N}$} & $-9,849^{* * *}$ & 3,346 \\
& & $(3,363)$ & $(3,282)$ \\
\hline Logaritmo de Verosimilitud & 555 & \\
\hline
\end{tabular}

a Logit condicional; la variable dependiente es el voto a un partido determinado. Los niveles de significación estadística son los siguientes: ${ }^{\star * *}$ p<0,01, ${ }^{* *}$ $p<0,05,{ }^{*} p<0,1$; entre paréntesis, errores típicos. 
Tabla A5.

Vitoria: el impacto de los candidatos en el voto, 1999, 2007 y 2011

\begin{tabular}{|c|c|c|c|c|c|c|c|}
\hline Variables & Partido & $\begin{array}{c}\text { PPI } \\
\text { PSOE }\end{array}$ & $\begin{array}{c}\text { IU/ } \\
\text { PSOE }\end{array}$ & $\begin{array}{l}\text { PNVI } \\
\text { PSOE }\end{array}$ & $\begin{array}{l}\text { UA/ } \\
\text { PSOE }\end{array}$ & $\begin{array}{c}\text { EH/ } \\
\text { PSOE }\end{array}$ & $\begin{array}{c}\text { EA-Bildu/ } \\
\text { PSOE }\end{array}$ \\
\hline \multicolumn{8}{|c|}{1999} \\
\hline
\end{tabular}

Valoración del candidato

$2,812^{* * *}$

$(0,717)$

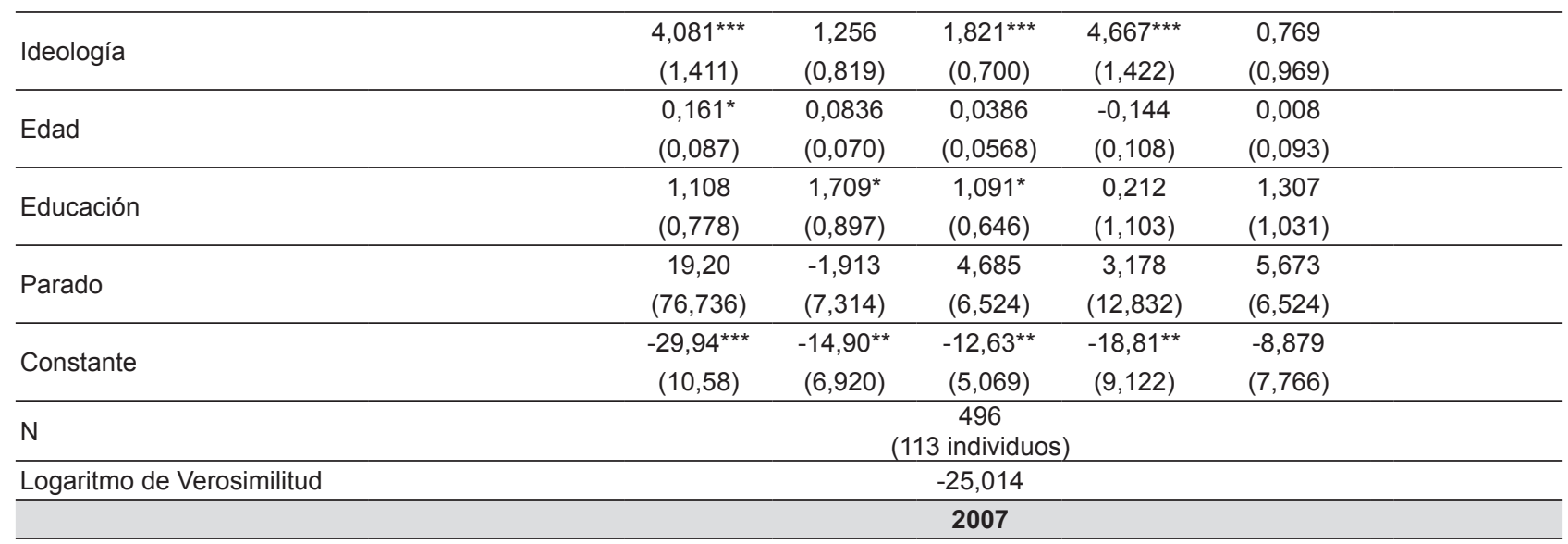

Valoración del candidato

$1,247^{* * *}$

$(0,105)$

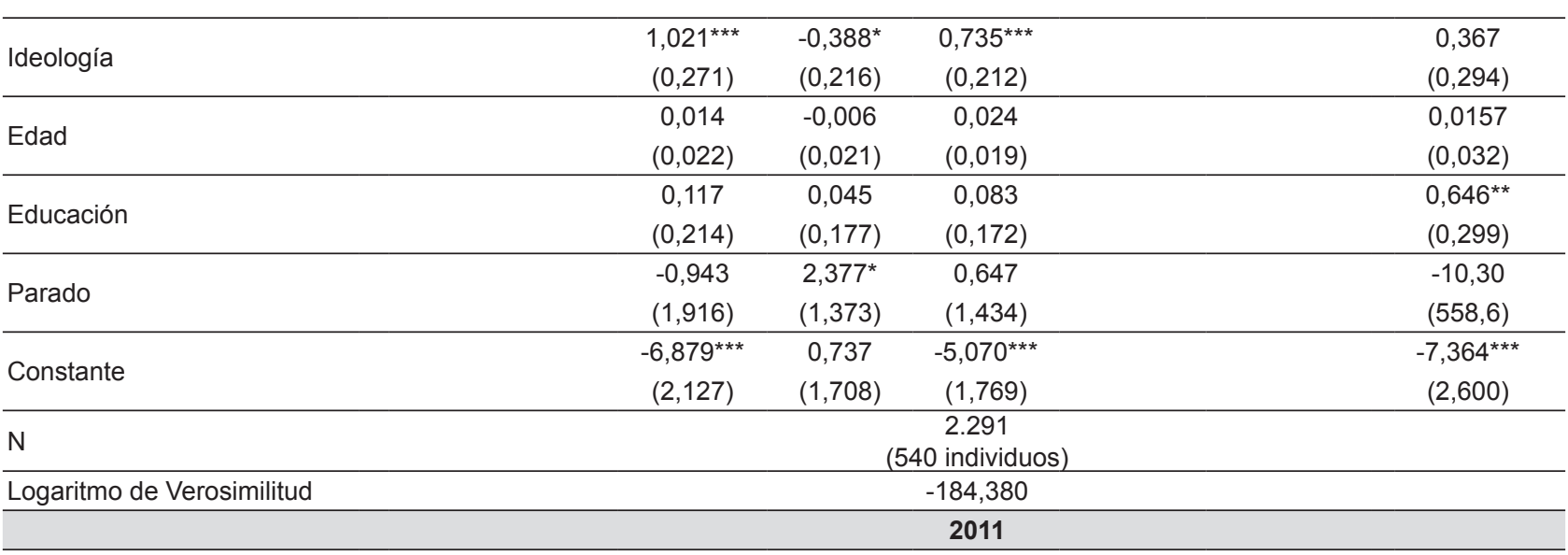

$\begin{array}{ll}\text { Valoración del candidato } & 1,031^{* * *} \\ & (0,167)\end{array}$

\begin{tabular}{lccc}
\hline Ideología & $\begin{array}{c}1,862^{* * *} \\
(0,426)\end{array}$ & $\begin{array}{c}0,774^{* *} \\
(0,314)\end{array}$ & 0,105 \\
\hline \multirow{2}{*}{ Edad } & 0,008 & 0,038 & $(0,271)$ \\
& $(0,028)$ & $(0,030)$ & $-0,134$ \\
Educación & $-0,360$ & 0,114 & $(0,398)$ \\
\hline \multirow{2}{*}{ Parado } & $(0,356)$ & $(0,384)$ & 2,747 \\
\hline \multirow{2}{*}{ Constante } & 1,622 & 1,034 & $(1,810)$ \\
\hline N & $(1,511)$ & $(1,609)$ & $-1,317$ \\
\hline Logaritmo de Verosimilitud & $-8,666^{* * *}$ & $-5,744^{*}$ & $(2,871)$ \\
\hline
\end{tabular}

a Logit condicional; la variable dependiente es el voto a un partido determinado. Los niveles de significación estadística son los siguientes: ${ }^{* \star \star}$ p<0,01, ${ }^{* \star}$ $p<0,05,{ }^{*} p<0,1$; entre paréntesis, errores típicos. 